Association for Information Systems AIS Electronic Library (AISeL)

2007

\title{
Crisis in the Information Systems Discipline: A Reflection
}

Sumit Bakshi

Indian Institute of Management Bangalore, sumitb03@iimb.ernet.in

S Krishna

Indian Institute of Management Bangalore, skrishna@iimb.ernet.in

Follow this and additional works at: http://aisel.aisnet.org/acis2007

\section{Recommended Citation}

Bakshi, Sumit and Krishna, S, "Crisis in the Information Systems Discipline: A Reflection" (2007). ACIS 2007 Proceedings. 27. http://aisel.aisnet.org/acis2007/27

This material is brought to you by the Australasian (ACIS) at AIS Electronic Library (AISeL). It has been accepted for inclusion in ACIS 2007

Proceedings by an authorized administrator of AIS Electronic Library (AISeL). For more information, please contact elibrary@aisnet.org. 


\title{
Crisis in the Information Systems Discipline: A Reflection
}

\author{
Sumit Bakshi and S. Krishna \\ Indian Institute of Management Bangalore \\ Email: \{sumitb03, skrishna\}@iimb.ernet.in
}

\begin{abstract}
This paper explores the issue of crisis in Information Systems discipline. It is argued that lack of a clearly shaped identity for the discipline is causing the problem of legitimacy and wide spread acceptance that IS discipline is facing. These problems put the discipline in crisis. Three dimensions of crisis are examined, viz., absence of core theories and concepts, lack of rigor and relevance in IS research outputs, and fragmented nature of IS research. It is concluded that IS research community must create an identity for itself for a better future.
\end{abstract}

\section{Keywords}

Information systems, Discipline, Rigor, Relevance, Crisis

\section{Introduction}

The discipline called Information Systems (IS) has its origins rooted more significantly in management than in the advancements in computer technology (Dickson, Benbasat, and King 1982). Seminal works like Barnard (1971) and Simon (1976) among others have placed a significant importance on the decision-making capabilities of organizations and the information requirements for this decision-making. Galbraith (1974) presented a view of organizations as information processing entities. It was proposed that greater the task uncertainty, greater the amount of information that must be processed among decision makers in order to achieve a given level of performance. The importance of information in organizational decision-making, and critical evaluation and research of information processing capabilities of organizations is widely acknowledged and accepted.

Kuhn (1970), in his seminal book 'The Structure of Scientific Revolutions', tried to identify the defining factors of a scientific discipline ${ }^{1}$. His idea of a paradigm, that describes a set of practices in a scientific discipline, was: what is to be observed and scrutinized, the kind of questions that are supposed to be asked and probed for answers in relation to this subject, how these questions are to be put, and how the results of scientific investigations should be interpreted. This definition of a scientific discipline is considered to be monistic and rigid by many social science researchers (e.g., Banville and Landry 1989; Galliers 2003; Huber and McDaniel 1986).

As discussed by Popper (1969), an academic discipline makes progress through refuting and refining theories that explain phenomena that come within its domain. This emphasizes the necessity of first defining what the scope of an academic discipline is. This definition should not be too restrictive as in the Kuhnian sense. Rather it should identify a set of broad concepts that would help in identifying the social problems that fall within the purview of the academic domain. Since most social problems are multidisciplinary in nature, the definition is necessary in order to resolve the grey areas of overlap and to identify which discipline would be the primary discipline and which would be the reference one. This clear definition of boundaries and identification of core concepts is necessary in order to give a direction to ongoing research efforts.

This paper critically reflects the current status of research on IS discipline and tries to comprehend the crisis of establishment of identity that the discipline is facing currently. Some causes are evaluated and consequences of lack of identity are pondered upon.

\section{Crisis in Information Systems Discipline}

An academic discipline establishes its identity among other disciplines on the basis of its contribution to the body of knowledge. This contribution comes when the discipline starts creating powerful, general theories about its core theoretical concepts (Popper 1969; Benbasat and Zmud 2003). The identity is corroborated by the rigor with which research is undertaken in the discipline and the relevance of the research topics to the real world (Lee 1991; Benbasat and Zmud 1999; Lyytinen 1999; Lee 1999; Rademacher 2001). This identity of the discipline is further strengthened when some common themes can be clearly seen as characterizing the research problems

\footnotetext{
${ }^{1}$ In this paper the terms discipline, field, and area are used interchangeably.
} 
(Benbasat and Weber 1996; Robey 1996; Weber 2003; Hirschheim and Klein 2003). Unequivocal answers to these pointers chalk out an identity of an academic discipline; clearer the answers are, more mature the discipline is considered to be.

The theoretical foundations of IS discipline have been questioned, found not to be so strong and are being thought upon again. From a long term perspective it is essential that foundations be periodically scrutinized as all disciplines must reinvent themselves to keep pace with the changing times. But this in no way undermines the importance of establishing a distinct identity for the discipline.

If an academic discipline lacks in any of the three parameters of core, rigor and relevance, and common theme, then its identity is not very well established and the academia finds it difficult to accept the research output generated by the discipline. This in-turn affects the ability of the discipline to find funding sources for its research endeavors. The lack of identity jeopardizes the career growth prospects of the researchers working in the field. This can have an adverse impact on attracting young, bright researchers to join the discipline.

The crisis faced by IS as an academic discipline is clearly visible from the table 1 below. It shows 15 business schools that featured among top ten in business school ranking by Financial Times, US News, and Business World. As can be seen in the table, only two out of these fifteen business schools have information systems as a core course for graduate level MBA program, rest all others have shifted IS courses to electives. A similar suit was followed two year back at Indian Institute of Management Bangalore when, after a comprehensive review of the graduate course structure, MIS was made an elective course. This reduces the teaching load significantly, thereby making it difficult to justify hiring new faculty members. When the academic job market for fresh $\mathrm{PhDs}$ in IS goes down, it will become difficult to attract students for the doctoral programs. This in turn affects the research potential and output from the discipline.

Table 1: IS as core course in various universities.

\begin{tabular}{|c|c|c|c|c|}
\hline University/School & $\begin{array}{l}\text { FT } \\
\mathbf{2 0 0 7}\end{array}$ & $\begin{array}{l}\text { US } \\
\text { News } \\
2007 \\
\end{array}$ & $\begin{array}{l}\text { BW } \\
2006\end{array}$ & $\begin{array}{l}\text { IS as } \\
\text { Core } \\
\text { Course? }\end{array}$ \\
\hline Wharton & 1 & 3 & 2 & No \\
\hline Harvard University & 3 & 1 & 4 & No \\
\hline Stanford University GSB & 4 & 2 & 6 & Yes \\
\hline Northwestern University (Kellogg) & & 5 & 3 & No \\
\hline University of Chicago GSB & 6 & 6 & 1 & No \\
\hline London Business School & 5 & & & Yes \\
\hline University of Michigan (Ross) & & & 5 & No \\
\hline MIT (Sloan) & & 4 & 7 & No \\
\hline Columbia Business School & 2 & 9 & 10 & No \\
\hline Insead & 7 & & & No \\
\hline Dartmouth College (Tuck) & 9 & 7 & & No \\
\hline UC Berkeley (Haas) & & 8 & 8 & No \\
\hline New York University (Stern) & 8 & 10 & & No \\
\hline Duke University (Fuqua) & & & 9 & No \\
\hline Yale School of Management & 10 & & & No \\
\hline
\end{tabular}

According to Popper (1969), academic fields make progress through refuting and refining theories that explain phenomena falling under the aegis of the field. One interpretation of this philosophy suggests that a theory is central in legitimizing the IS field. Whitley $(1984)^{2}$ said that theories vary significantly across academic areas in social sciences and no uniform relationship can be established between a given field and a specific theoretical core.

It is perceived that an established identity will imply stability in the set of core characteristics. Another view conceived by Gioia et al (2000) visualizes identity to be relatively fluid and unstable concept. A paradigmatic identity labels the basic assumptions of a researcher's purpose of activity, the character of the examined object, and the suitable methodology for examining the objects (Scherer 2003). The stability of identity is contained in the stability of these labels that are used to express the identity, but the meaning associated with these labels change rendering the identity to be mutable. They argue that rather than being rigid, identity of an academic discipline should have 'adaptive instability' which makes it easier to keep the discipline in tune with the changing environmental conditions. Adaptive instability presupposes the existence of an identity. It is rather a

\footnotetext{
${ }^{2}$ As referred in Lyytinen and King (2004).
} 
caution against being rigid and non-receptive to newer ideas and challenges than advocating having no identity at all.

Having established the significance of an established identity for an academic discipline we now try and figure out what is the status of Information Systems discipline on these dimensions.

\section{Absence of Core IS Theories and Concepts}

The second editor-in-chief of the Journal Information Systems Research, John King, commented on the IS field saying

“...it is arguable that information systems is probably not even a field, but rather an intellectual convocation that arose from the confluence of interests among individuals from many fields who continue to pledge allegiance to those fields through useful ties of many kinds. ...Our leading publications contain many articles that could as easily and appropriately have been published in journals from computer science, applied mathematics, economics, organizational studies, psychology, and so on."3

It is very well acknowledged among the information systems researchers that the IS discipline lacks a set of core concepts and theories relating the concepts that is acceptable to all. Some researchers are in favor of establishing a core paradigm and strictly scrutinizing research topics for confluence with the paradigm. Others argue that this lack of a core provides the discipline with flexibility that fosters new ideas and fields to explore. While a core is required, micro focus on it is potentially dangerous. They contend that establishing a rigid core might kill the ability of the discipline to adapt to rapidly changing environment (Robey 2003; Agarwal and Lucas 2005; Alter 2003a).

Many researchers have attempted to define what the core concepts of IS discipline are and what is the relationship among them (Benbasat and Zmud 2003; Mason and Mitroff 1973; Orlikowski and Iacono 2001; Ives, Hamilton and Davis 1980; Gorry and Scott Morton 1971). The efforts were motivated by the idea that a core will strengthen the IS discipline creating a distinct identity of IS research, will bind the efforts of IS researchers, and set forth the cumulative tradition in IS research. This model of core concepts would put the reliance of IS researchers on the reference disciplines in a clearer focus. We will know exactly what we are borrowing from other discipline and why.

Whinston and Geng (2004) identified that a large gray area of problems exists whose relevance and relation with IS discipline is debatable. This gray area includes problems related to objects that are hard to classify clearly as IT or non-IT artifacts, and the problems that are deeply entrenched into another well-established discipline at the same time. These debatable research topics make the discipline 'weaker' as compared to the other 'mature' disciplines that have much smaller gray area. A set of core IS concepts and theories acceptable to all will help us reduce this gray area. By establishing links of a new topic with the core we can adjudge its distance from the core and thus decide whether the topic should be representative of IS discipline or it is better suited to be taken under some other discipline.

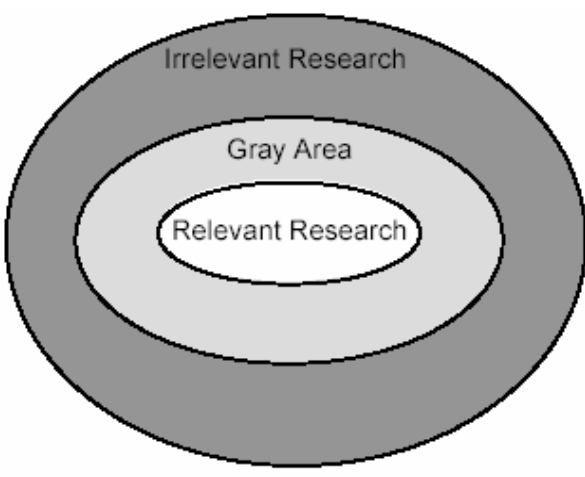

(a) IS Discipline

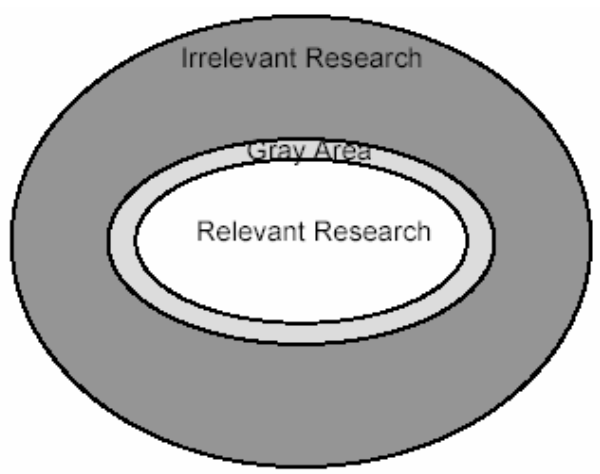

(b) A Benchmark Mature Discipline

Figure 1: Relevant Research, Irrelevant Research and Gray Area (Whinston and Geng 2004)

Benbasat and Zmud (2003) argue that

“... topical diversity can, and has, become problematic in the absence of a set of core properties, or central character, that connotes, in a distinctive manner, the essence of the IS discipline. If influential

\footnotetext{
${ }^{3}$ As quoted by Robey (1996).
} 
stakeholders are unable to comprehend the nature, importance, and distinctiveness of the role being served by the IS discipline, these stakeholders are unlikely to acknowledge its legitimacy within the organizational field."

Weber (1987) too argued that disciplines attain identity and maturity among peers only when they have succeeded in developing at least one powerful, general theory binding the defining concepts of the discipline and when it is recognized that the theory is not very closely related to any other discipline but the owner. Pfeffer warns that without a strong theoretical core we are prone to hostile takeover from within or from outside and whatever we consider distinctive would be irretrievably lost. ${ }^{4}$

Weber (2003) took Benbasat and Zmud's (2003) argument a step further and cautioned that after identifying core phenomena of IS discipline, we need to check whether the phenomena can be satisfactorily accounted for by the theories provided by other disciplines. If such phenomena and related theories are included in the core, then we will be characterized as a reference-theory discipline forever. In extreme circumstances the IS discipline may be dissolved and merged with the reference disciplines. To prevent this, Hirschheim and Klein (2003) propose developing a Body of Knowledge in information systems.

An attempt was made in Alter (2003b) to pin point the origin of crisis by preparing a cross-tab of seven different types of customers of the IS research and five forms of IS research output. He found that only two of the seven types of customers are creating the crisis and thus a repositioning of boundaries rather than tighter definition is the solution. The analysis fails to consider the relative impact of these customers on the research output, which can seriously alter the findings.

King and Lyytinen (2004) say that irrespective of the status of IS theories, the field has established an identity of its own by consistently focusing on the systematic processing of information in human enterprises. They argue that IS field faces the problem of academic legitimacy and not that of academic identity. In another paper Lyytinen and King (2004) show that the claim that if there is a theoretical core then IS discipline gains legitimacy, is valid but the claim that lack of theoretical core deprives IS discipline of legitimacy, is invalid. They suggest that the IS field needs intellectual discipline in boundary spanning across a 'market of ideas' concerning the application of information technology in human enterprises. The theoretical core does not deprive, but its existence does help the discipline gain legitimacy. Therefore we must try and establish an identity for us; legitimacy for the discipline will surely follow.

It is argued that the lack of core theoretical framework gives researchers much more freedom to explore newer areas and makes the discipline richer. But this freedom causes lot more conflicts than the freedom it provides. Most of the IS researcher do not agree on the constituents of the IS discipline and are receptive to conflicting or non-overlapping ideas. Whinston and Geng (2004) describe this situation from the point of the peer review of research. As the number of reviewers increase, it becomes more and more difficult to find a topic acceptable to all of them. This internal policing forces the IS researchers to choose conservative topics. Thus the freedom is, unintentionally, limiting the research.

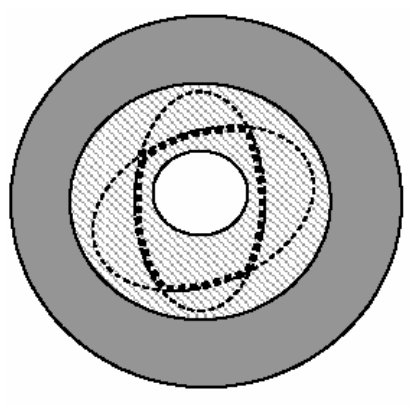

(a) Two Reviewers

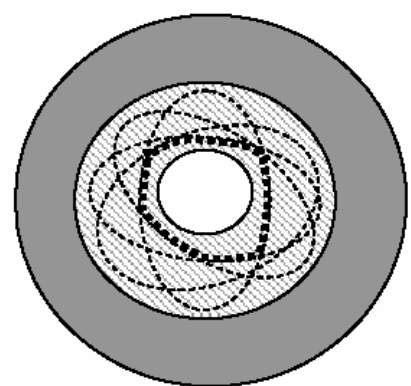

(b) Four Reviewers

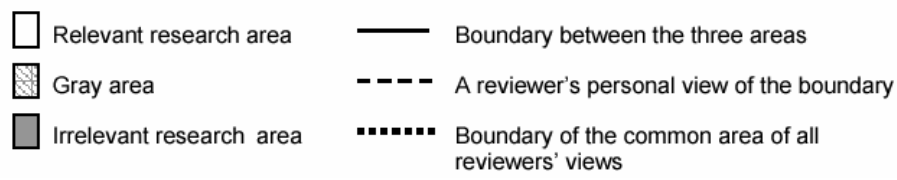

Figure 2: The dissection of Gray area makes topic selection very difficult (Whinston and Geng 2004)

IS as a discipline, has been in existence for over 30 years now. It is time now that we create theories that are distinctive to IS discipline only and provide us a much stronger foundation that we stand on today. This is not

\footnotetext{
${ }^{4}$ As quoted by Benbasat and Weber (1996).
} 
going against multidisciplinary research. It just means that we should shun our complete dependence on reference disciplines for every research performed in IS. Rather we borrow theoretical frameworks from other disciplines to corroborate and triangulate our findings. This way we would be working towards strengthening or critically evaluating, questioning the foundations of IS discipline and our research efforts would be useful to us and not to other disciplines. As Baskerville and Myers (2002) feel

"IS has come of age. Perhaps the time has come for IS to become a reference discipline for others."

\section{Problem of Rigor and Relevance in IS Research}

Due to the wide variety in the topics researched and methodologies employed, the academia perceives the research outcome of IS discipline to be lacking in academic rigor. In addition the relevance of the topics to the real world and to the central body of knowledge is also questioned. If a topic is highly relevant to practitioners, it is labeled weak academically. If some research is done very rigorously, then its incremental value addition is labeled miniscule. Thus the balance between rigor in research and the relevance of the topic is very important consideration for the acceptance of the research outcome by peers and practitioners alike.

The concept of rigor emerges from the core of positivist beliefs that the reality is objective in nature and must be studied objectively. These objective realities are supposed to yield hard objective facts that when mathematically analyzed, prove the existence of the reality beyond any shadow of doubt. Baroudi and Orlikowski (1989) surveyed leading MIS journals and found that the statistical power of MIS research was substantially below average. In addition, any research that focuses on soft facts and tries to present an interpretive account of the reality was taken to be less rigorous. But the trend is now changing. Interpretive and multidisciplinary research approaches which are more suited for IS research questions (Orlikowski and Baroudi 1991), done rigorously are now widely accepted. This is evident in the rising trend of interpretive research publications in the leading journals. Use of multidisciplinary approach is also on a rise. This triangulates the topic from potential pitfalls and also adds to the rigor in research (Holland 2003). In social sciences, rigor is thought to embrace six elements: properly theorized questions, clearly defined concepts, method appropriate to the question and to the context, good technique involving careful execution, subjected to attempts of 'disconfirmation', and open to checking (not replication) (Castleman 2000) ${ }^{5}$.

The problem of relevance of research still remains. A research outcome would be relevant if it either adds to the current theoretical frameworks of the discipline or if it solves a real life problem faced by practitioners and improves their work efficiency and effectiveness. A research problem that reconfirms originally established frameworks by fine-tuning some of the variables would indeed be very rigorous, but the value addition from it would be very less. Thus relevance could be taken as cost-benefit analysis of a research topic. More the research outcome is supposed to change theoretical framework or work practices, more relevant the research is. A proper balance between rigor and relevance needs to be struck. Davenport and Markus (1999) suggest accepting the concept of 'impact frontier', that is, highly relevant research articles may have the same impact quotient as highly rigorous ones.

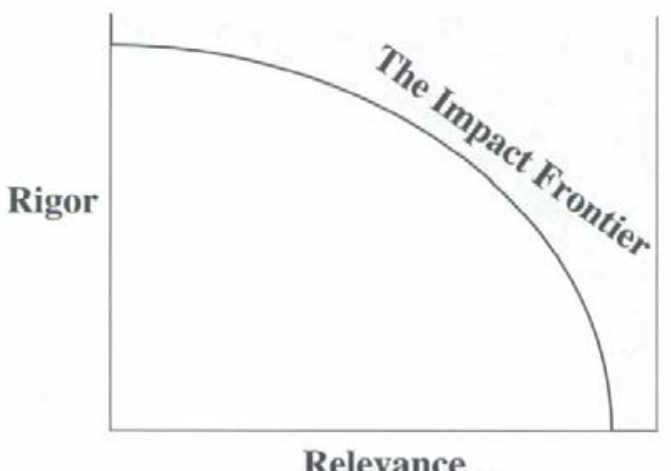

Relevance

Figure 3: Rewarding Rigor and Relevance (Davenport and Markus 1999)

Academia is generally skeptical about applied research. Many universities do not consider publications in practitioner journals as academic publication when reviewing the performance of academicians. The rigor in IS research is already at question, so IS researcher are forced to take up research topics that score high on rigor but lack relevance to practice. These stakeholders from within the discipline become more important than external stakeholders as they control the advancement of IS researchers and the field as a whole (Hirschheim and Klein

\footnotetext{
${ }^{5}$ As quoted by Hirschheim and Klein (2003).
} 
2003). The pressure could be stronger for junior IS faculty if they knew that their tenure decision is in hands of non-IS faculties. They would be forced to take up 'academic' research and shun all 'non-academic' activities.

The lack of credibility for IS research among business community is described well by Benbasat and Zmud (1999). They describe the 1995 decision of Society of Information Management (SIM) to stop including a subscription of MIS Quarterly as part of member fees. Very few members continued the subscription that was available now at additional cost. That's when the leading journal of the discipline, MIS Quarterly, asserts that it adopted different strategies to

$$
\text { “... walk this tight rope between rigor and relevance” (Zmud 1996b). }
$$

Even today there is no IS journal that fills this gap of providing literature relevant to practitioners. We do not have any journal that can match Harvard Business Review or Sloan Management Review. The practitioneroriented magazines available on stands are all technology focused with very little relevant material for information systems manager. They fail to provide an extensive coverage of problems faced by IS practitioners. The number of IS researchers publishing in these is also far too few. Using co-word analysis, Larsen and Levine (2005) found 62 different 'centers of coherence' in their study of IS academic journals. They found that evidence of theory building was extremely weak and that a cumulative tradition in IS research as explained by Benbasat and Zmud (1999), was still absent.

Zmud (1996a) expresses frustration over the lack of studies that describe today's IT management and IT usage contexts. The research topics do not reflect the current 'buzz'. Benbasat and Zmud (1999) define relevant research to be implementable, synthesizing existing body of research, and stimulating critical thinking. This requires the researcher to acquire a pragmatic rather than academic tone. They provide five explanations for lack of relevance, emphasis on rigor over relevance, lack of a cumulative tradition, dynamism of information technology, limited exposure to relevant contexts, and institutional and political factors. The lack of cumulative tradition again points to absence of core theoretical framework in IS discipline. Prevalence of multiple theoretical paradigms makes it very difficult to assimilate all of them into one and then taking it forward.

In response, Lee (1999) looks at the Kuhnian explanation of inquiry in natural sciences and argues that even if IS researchers look closely at practitioners to identify potential research topics, they might successfully explain only what practitioners are already doing. He says that an academician's responsibility goes beyond practitioners, to the society in general. Davenport and Markus (1999) suggest that the methods of consultants should be studied closely, improved, and embraced, as they are much faster at identifying practitioner's needs for research and aim at producing good, if not rigorous research outputs.

Another interesting perspective here is provided in DeSanctis (2003). This paper perceives research to be a process enacted within a community of practice. This view regards a discipline to be more akin to a voluntary association than a formal organization (Knoke and Prensky 1984). DeSanctis argues that for a community of practice, formal structures cannot be dictated but they evolve from the participants' actions. So, greater focus should be on internal matters than on external legitimacy.

Thus we see that rigor and relevance are important dimensions of quality of research output and strongly related to the perceived identity of a discipline. But rigor and relevance emanates from the research questions posed and researched. The rigor of interpretive methodologies prevalent in IS research is now well acknowledged but we still need to work on producing research outputs that have a greater relevance to academia and practitioner community as well. We need to work on, as Davis (1971) pointed out, 'interesting' theories.

The focus on 'academic' research helped considerably in gaining legitimacy for IS research from other disciplines, but it has taken the IS researcher away from the field which has been in a constant state of flux due to rapid developments in technology. The IS practitioners accuse IS researchers of not knowing the ground realities rendering the research outcome to be irrelevant for the field. The IS discipline must now think very carefully about the balance between academically relevant and applied research. IS being an applied discipline can’t afford to stay distant from practical problems.

\section{Fragmented Nature of IS Research}

Rapid advancements in technology are creating newer areas of interest for IS researchers. The discipline has evolved from the study of data processing system to management information system to information system. And now the latest developments in communication technology are changing the research interests to Information and Communication Technology (ICT). This change is not so much related to technology as to usage patterns associated with them (Hirschheim and Klein 2003).

Hirschheim and Klein (2003) believe fragmentation to be the root cause of the potential crisis looming on IS field. Banville and Landry (1989) feel IS to be essentially pluralistic scientific field, especially in view of its 
vocational character. They call IS to be a 'fragmented adhocracy' and perceive it to be a major strength of the field.

Dahlbom (1996) identified four distinct stages of computer technology use. Starting as computing machines, they were used as information systems by 60's for their capability to handle large amounts of data. In the next stage personal computing came and with client-server technology changed the way coordination and cooperation activities were performed. Finally with the advent of Internet, computer became a medium to communicate, educate, and entertain as well.

The variety of issues taken to be critical in information systems management has been captured very well in the surveys done by Niederman, Brancheau, and Wetherbe (1991). Their survey when compared to two earlier surveys done jointly by Society for Information Management (SIM) and MIS Research Center (MISRC), University of Minnesota, presents a clear picture of the diverse interests prevalent in IS research. They found that over the decade of 1980, three issues were replaced from the list of top ten critical issues at the beginning of the decade, by the decade end; two were replaced in the third quadrant while one new issue made it to top ten in the last quadrant of the decade. The issues themselves vary over information architecture, IS-organization alignment, competitive advantage, organizational learning, IS human resources, etc. If a similar study is done today, we will definitely see a large churn of topics again. A keyword classification scheme developed by Barki et al (1993) found nine different classes of keywords from IS research literature.

As already pointed that IS discipline is inherently pluralistic, is this diversity in problems researched, good for the discipline? It is argued that diversity expands the discipline's foundation and attracts good people (Robey 1996). But for this diversity to remain IS researchers must bear the responsibility of 'disciplined methodological pluralism' (Landry and Banville 1992) and clearly justify their research aims, theories, and methods. Towards extreme Robey (1996) called the efforts of unification to build institutional legitimacy as resorting to political tactic.

Benbasat and Weber (1996) consider diversity to be harmful for the long-term viability of IS as a discipline. Diversity they defined as diversity in problems addressed, theoretical foundations that guide our research, and methods used on data collection and analysis. While agreeing that diversity helped improve rigor, they feel that the diversity now threatens the existence of IS discipline.

Considering the dimensions of diversity as mentioned by Benbasat and Weber (1996), we can argue that the dimensions have different impacts. Diversity in methods employed for collection and analysis of data in fact should be sought after as it improves the rigor in research greatly. A multidisciplinary approach triangulates the inferences drawn from the research. It provides the ability to analyze and understand the topic in hand from multiple perspectives. This is of utmost important in social sciences as every phenomenon is affected greatly by the context within which it is taking place. Minute changes in the context may produce totally different outcomes from the phenomenon. In IS terms, an IS implementation in one setting if done identically in another setting, may or may not work. The number of variables involved in the success of IS implementation is so large that a multidisciplinary approach is a must for a better understanding of it.

Diversity in the problems addressed stems from the lack of clear identification of the conceptual constitution of the IS discipline. If one doesn't know where to go then any road will take him there. If the basic, core constituents of the discipline are not identifiable, then any research topic even quite distantly related would be included in the discipline. These 'errors of inclusion' further dilute the identity creating a vicious circle. Similarly the differences of opinions would force some 'errors of exclusion' too, in which some research topics that might be related to the discipline are left out. Thus as already shown above in Fig 2, this forces IS researchers to go conservative, choking the search for newer frontiers.

Diversity in theoretical foundations adopted highlights the over dependence of IS researchers on the reference disciplines for frameworks to analyze research topics. Since we do not have any theoretical framework to call our own, we rely on borrowing them from other disciplines. This is not a problem if done for adding rigor to the research. The borrowing should be done when the analysis of the research topic remains incomplete using the theories belonging to the discipline. When this practice becomes common, researchers will not try the hard work required to build theories for the discipline. They will take the easy way out and borrow a framework from a reference discipline. Thus the research would strengthen the reference discipline at the cost of efforts of an IS researcher. In this the IS discipline stands to loose. Borrowing frameworks is also acceptable at least when all researchers agree upon the core theoretical concepts defining the discipline. Benbasat and Weber (1996) quote Jeffery Pfeffer saying

“... disagreement in theoretical approaches and even methodology will not prove detrimental as long as there is some agreement about what the fundamental questions or issues are and as long as there are some agreed upon ways of resolving theoretical and methodological disputes." 
When all research frameworks of IS discipline are borrowed from other disciplines, anyone can raise objections about inclusion of that research to IS discipline, as it generally happens, and we find it very difficult to defend ourselves. This diversity in theoretical frameworks raises serious questions on the existence of the IS discipline itself. Why should the IS discipline exist? Why should it not be dissolved and the IS researchers and academicians be included in the reference disciplines they have been working with? The answers to these questions are neither easy nor short. As identified by Benbasat and Zmud (2003), we lack cognitive legitimacy and thus have to resort every now and then to the socio-political legitimacy we gained by piggybacking the advents of information technology. Thus universities will continue the IS departments and run IS degree programs, but the legitimacy of the output from these departments will always be questioned.

\section{Conclusion}

Information Systems as an academic discipline has come a long way. The debate on whether and to what extent IS discipline is facing a crisis and what are the characteristics of this crisis is an extensive and ongoing topic. Information Systems as a discipline is at a crucial stage where it needs to consider its future development very carefully and take concrete actions to secure it. Thanks to information and communication technology advancing by leaps and bounds, IS departments are a part of every major university. At the same time, IS courses are disappearing from core curriculum. This puts pressure on IS faculty to work hard and smart to gain legitimacy among management researchers, academics, and practitioners.

The IS discipline as of now neither has neither a concrete theoretical foundation nor any theories and concepts that are accepted by all IS researchers as forming the core. There are arguments on both sides as to whether this lack of core is good or bad for the discipline. Lack of core has lead to great diversity in topics researched by the community. On the other hand it has made it difficult to fathom for most IS faculty members. This diversity in turn makes the discipline less intelligible for members of other disciplines. Due to this variety the research output of the IS community are also questioned, considered less rigorous, and their relevance to academia and practitioners is doubted. Per contra, some researchers consider it to be an opportunity to carry out rigorous research and argue that IS research should religiously guard this diversity.

Weighing both sides carefully we conclude that IS discipline lacks an identity and this could have adverse effects on the members of the community in terms of academic career advancements and future prospects. It also acts as a deterrent for prospective members from joining the community. Due to the discontinuity in transferring knowledge created by IS academia to all the IS practitioners, the sources of funding for IS research efforts are few and they too are in jeopardy. Thus it is necessary that IS community, researchers and practitioners alike, to come together and define an identity for ourselves.

\section{References}

Alter, S, 2003a, 'Sidestepping the IT Artifact: Scrapping the IS Silo, and Laying Claim to Systems in Organizations' Communications of the Association for Information Systems, vol. 12, no. 30.

Alter, S, 2003b, 'The IS Core - XI: Sorting Out Issues About the Core, Scope, and Identity of the IS Field', Communications of the Association for Information Systems, vol. 12, no. 41.

Agarwal, R, \& Lucas Jr., HC, 2005, ‘The Information Systems Identity Crisis: Focusing On High-Visibility And High-Impact Research’, MIS Quarterly, vol. 29, no. 3, pp. 381 - 398.

Banville, C, \& Landry, M, 1989, 'Can the Field of MIS be Disciplined?', Communication of the ACM, vol. 32, no. 1 , pp. $48-60$.

Barki, H, Rivard, S, \& Talbot, J, 1993, 'A keyword Classification Scheme for IS Research Literature: An Update’, MIS Quarterly, vol. 17, no. 2, pp. 209 - 226.

Barnard, CI, 1971, Functions of the Executive, Harvard University Press, Cambridge.

Baroudi, JJ, \& Orlikowski, WJ, 1989, ‘The Problem of Statistical Power in MIS Research’, MIS Quarterly, vol. 13, no. 1, pp. $87-106$.

Baskerville, RL, \& Myers, MD, 2002, 'Information Systems as a Reference Discipline', MIS Quarterly, vol. 26, no. 1 , pp. $1-14$.

Benbasat, I, \& Weber, R, 1996, 'Research commentary: Rethinking "Diversity" in Information Systems Research', Information Systems research, vol. 7, no. 4, pp. 389 - 399.

Benbasat, I, \& Zmud, RW, 2003, 'The Identity Crisis Within The IS Discipline: Defining And Communicating The Discipline’s Core Properties’, MIS Quarterly, vol. 27, no. 2, pp. 183 - 194. 
Benbasat, I, \& Zmud, RW, 1999, ‘Empirical Research In Information Systems: The Practice Of Relevance’, MIS Quarterly, vol. 23, no. 1, pp. 3 - 16.

Castleman, T, 2000, 'Rigor vs. Relevance in Sociological Research', Paper presented at the panel session Rigor Vs Relevance In IS Research, $8^{\text {th }}$ European Conference On Information Systems, Vienna, Austria.

Dahlbom, B, 1996, 'The New Informatics', Scandinavian Journal of Information Systems, vol. 8, no. 2, pp. 29 48.

Davenport, TH, \& Markus, LM, 1999, 'Rigor vs. Relevance Revisited: Response To Benbasat And Zmud', MIS Quarterly, vol. 23, no. 1, pp. 19 - 23.

Davis, MS, 1971, ‘That’s Interesting!’, Philosophy of Social Science, vol. 1, pp. 309 - 344.

DeSanctis, G, 2003, 'The Social Life of Information Systems Research', Journal of the Association for Information Systems, vol. 4, no. 7, pp. 360 - 376.

Dickson, GW, Benbasat, I, \&, King, WR, 1982, 'The Management Information Systems Area: Problems Challenges And Opportunities’, ACM SIGMIS Database, vol. 14, no. 1, pp. 7 - 12.

Galliers, RD, 2003, 'Change As Crisis Or Growth? Toward A Trans-Disciplinary View Of Information Systems As A Field Of Study’, Journal of the Association for Information Systems, vol. 4, no. 6, pp. 337 - 351.

Galbraith, JR, 1974, 'Organizational Design: An Information Processing View', INTERFACES, vol. 4, no. 3, pp. $28-36$.

Gioia, DA, Schultz, M, \& Corley, KG, 2000, 'Organizational Identity, Image and Adaptive Instability', Academy of Management Review, vol. 25, no. 1, pp. $63-81$.

Gorry, GA, and Morton, MSS, 1971, ‘A Framework for Management Information Systems’, Sloan Management Review, vol. 13, no. 1, pp. 55 - 70.

Hirschheim, R, \& Klein, HA, 2003, 'Crisis in the IS Field? A Critical Reflection on the State of the Discipline', Journal of the Association for Information Systems, vol. 4, no. 5, pp. 237 - 293.

Holland, CP, 2003, 'The IS Core - X, Information Systems Research And Practice: IT Artifact Or A Multidisciplinary Subject?', Communications of the Association for Information Systems, vol. 12, no. 40.

Huber, GP, \& McDaniel, RR, 1986, 'The Decision-Making Paradigm of Organizational Design’, Management Science, vol. 32, no. 5, pp. $572-589$.

ISWorld, MIS Journal Rankings, viewed 3 May 2006, <http://www.isworld.org/csaunders/rankings.htm>

Ives, B, Hamilton, S, \& Davis, GB, 1980, 'A Framework for Research in Computer-Based Management Information Systems’, Management Science, vol. 26, no. 9, pp. 910 - 934.

King, JL, \& Lyytinen, K, 2004, 'Reach and Grasp’, MIS Quarterly, vol. 28, no. 4, pp. 539 - 551.

Knoke, D, \& Prensky, D, 1984, 'What Relevance Do Organizational Theories Have For Voluntary Organizations?’, Social Science Quarterly, vol. 65, no. 1, pp. 3 - 20.

Kuhn, TS, 1970, Structure of Scientific Revolutions, $2^{\text {nd }}$ ed., University of Chicago, Chicago.

Landry, M, \& Banville, C, 1992, 'A Disciplined Methodological Pluralism for MIS Research', Accounting, Management and Information Technologies, vol. 2, no. 2, pp. 77 - 97.

Larsen, TJ, \& Levine, L, 2005, 'Searching For Management Information Systems: Coherence And Change In The Discipline’, Information Systems Journal, vol. 15, no. 4, pp. 357 - 381.

Lee, AS, 1991, 'Integrating Positivist and Interpretive Approaches to Organizational Research', Organization Sciences, vol. 2, no. 4, pp. $342-365$.

Lee, AS, 1999, 'Rigor and Relevance in MIS Research: Beyond the Approach of Positivism Alone', MIS Quarterly, vol. 23, no. 1, pp. 29 - 34.

Lyytinen, K, 1999, 'Empirical Research In Information Systems: On The Relevance Of Practice In Thinking Of Is Research’, MIS Quarterly, vol. 23, no. 1, pp. 25 - 28.

Lyytinen, K, \& King, JL, 2004, 'Nothing at the Center?: Academic Legitimacy in the Information Systems Field', Journal of the Association for Information Systems, vol. 5, no. 6, pp. $220-246$. 
Mason, RO, \& Mitroff, II, 1973, ‘A Program for Research of Management Information Systems', Management Science, vol. 19, no. 5, pp. $475-487$.

Niederman, F, Brancheau, JC, \& Wetherbe, JC, 1991, 'Information Systems Management Issues for the 1990s', MIS Quarterly, vol. 15, no. 4, pp. 475 - 500.

Orlikowski, WJ, \& Baroudi, JJ, 1991, 'Studying Information Technology in Organizations: Research Approaches and Assumptions’, Information Systems Research, vol. 2, no. 1, pp. 1 - 28.

Orlikowski, WJ, \& Iacono, SC, 2001, ‘Research Commentary: Desperately Seeking the “IT” in IT Research - A Call to Theorizing the IT Artifact’, Information Systems Research, vol. 12, no. 2, pp. 121 - 134.

Popper, K, 1969, Conjectures and Refutations: The Growth of Scientific Knowledge, Harper \& Row, London.

Rademacher, R, 2001, 'The Changing Profile Of Information Systems Research: 1995-2000', Journal of Computer Information Systems, vol. 42, pp. 1, pp. 13 - 16.

Robey, D, 1996, 'Research Commentary: Diversity in Information Systems Research: Threat, Promise, and Responsibility’, Information Systems Research, vol. 7, no. 4, pp. 400 - 408.

Robey, D, 2003, 'Identity, Legitimacy And The Dominant Research Paradigm: An Alternative Prescription For The IS Discipline’, Journal of the Association for Information Systems, vol. 4, no. 7, pp. 352 - 359.

Scherer, AG, 2003, 'Modes of Explanation in Organization Theory’, In The Oxford Handbook of Organization Theory, eds. Tsoukas, H, \& Knudsen, C, Oxford University Press.

Simon, HA, 1976, Administrative Behaviour: A Study Of Decision-Making Processes In Administrative Organization, Free Press, New York.

Weber, R, 1987, 'Toward A Theory Of Artifacts: A Paradigmatic Base For Information Systems Research', Journal of Information Systems, vol. 1, no. 2, pp. 3 - 19.

Weber, R, 2003, 'Editor’s comments: still desperately seeking the IT artifact', MIS Quarterly, vol. 27, no. 2, pp. iii - xi.

Whinston, AB, \& Geng, X, 2004, 'Operationalizing the Essential Role of the Information Technology Artifact in Information Systems Research: Gray Area, Pitfalls, And The Importance Of Strategic Ambiguity’, MIS Quarterly, vol. 28, no. 2, pp. 149 - 159.

Whitley, R, 1984, The Intellectual and Social Organization of Sciences, Clarendon Press, Oxford.

Zmud, RW, 1996a, ‘Editor's Comments’, MIS Quarterly, vol. 20, no. 2, pp. xxi-xxiii,

Zmud, RW, 1996b, ‘Editor's Comments’, MIS Quarterly, vol. 20, no. 3, pp. xxxvii-xxxviii.

\section{Copyright}

Sumit Bakshi and S Krishna (C) 2007. The authors assign to ACIS and educational and non-profit institutions a non-exclusive licence to use this document for personal use and in courses of instruction provided that the article is used in full and this copyright statement is reproduced. The authors also grant a non-exclusive licence to ACIS to publish this document in full in the Conference Proceedings. Those documents may be published on the World Wide Web, CD-ROM, in printed form, and on mirror sites on the World Wide Web. Any other usage is prohibited without the express permission of the authors. 